\title{
An Ontology-Based Predictive Maintenance Tool for Power Substation Faults in Distribution Grid
}

\author{
Moamin A. Mahmoud ${ }^{1}$, Alicia Y.C. Tang ${ }^{2}$ \\ Institute of Informatics and Computing in Energy \\ Universiti Tenaga Nasional \\ Kajang, Malaysia
}

\author{
Kuganesan Kumar $^{3}$ \\ Graduate School of Business \\ Universiti Kebangsaan Malaysia \\ Bangi, Malaysia
}

\author{
Nur Liyana Law Mohd Firdaus Law ${ }^{4}$ \\ Mathuri Gurunathan ${ }^{5}$ \\ College of Computing and Informatics \\ Universiti Tenaga Nasional, Kajang, Malaysia
}

\author{
Durkasiny Ramachandran ${ }^{6}$ \\ College of Engineering \\ Universiti Tenaga Nasional \\ Kajang, Malaysia
}

\begin{abstract}
Recent advances in Power Grid (PG) technology pose an important problem of measuring the effectiveness of power grid configurations. Current assessment models are not adequate to mitigate the setup issues due to the absence of a highfidelity evaluation framework that can consider diverse scenarios based on the market interest. Consequently, we develop a highly flexible Ontology-based Evaluation System that can accommodate and assess different scenarios. The use of ontology as middleware is the best approach to produce an efficient, semantically aware, and operationally accurate system environment for managing flexibility in evaluation. The evaluation is made by predicting the failure intensity and subsequently generate a maintenance report of a particular configuration. The selection of the best configuration is made by comparing the maintenance report of different configurations. The developed evaluation system consists of three main components which are Configuration Generator Tool (GCT), Failure Prediction Model (FDM), and Hybrid Simulation Platform (HSP). The GCT is a knowledge-based system that provides a powerful tool for engineers to generate alternative configurations. The GCT data were collected from literature, validated by experts, and modeled using Web Ontology Language (OWL). While the HSP was developed using several modelings and ontology-based tools such as blender 3D modeling, unity 3d, asp.net, my sql, and apache Jena fuseki. Finally, the FDM was developed based on the impact and relationship of odd events to power grid components and the impact of a failed component to other components, the prediction is modeled using two methods Poisson Model and Likelihood Estimation Method.
\end{abstract}

Keywords-Predictive maintenance; ontology; power substation faults; distribution grid

\section{INTRODUCTION}

The Energy Power Grid Ontology development proposed in this paper is expected to allow the sharing of ontology among applications and stakeholders. Utilizing a similar lexicon, the normal issues that happen during application interoperability will be anticipated and fathomed. Ontologies development that covers domain and application characteristics can be utilized to not as it bolstered systems integration by utilizing standardized vocabularies but to system advancement by reusing these ontologies. As such, the use of ontology for the energy power grid is very important in order to allow for applications to inter-operate and stakeholders to share knowledge [13] [14] [21].

Ontologies have been effective in integrating the knowledge needed for tackling complex issues, for example, energy management issues. The ontology usage as middleware is the most ideal approach to manage produce a semantically aware, productive, and operationally accurate program atmosphere for directing flexibility in the distribution system. A typical lexicon and information model helps ease the exertion needed for programming software antiques to communicate viably with others within the energy management framework [11] [12]. Another application is ontology in agent communication language in complex systems [23] [24] [25] [26] [27].

Fault occurrences in the distribution systems are due to multiple reasons, such as human mistakes, components failure, lightning strikes, or infrastructure aging. These marvels are basic and proactive activity. Hence, exact data of the fault area plays a crucial part in speeding up the reclamation process, after being exposed to any sort of fault in power distribution grids [1]. Techniques for fault detection, location, and classification, are in transmission lines and distribution networks have been intensively considered over the long term. With the ideas related to power grid drawing in developing concern among analysts, the significance of building an intelligent fault monitoring and analysis framework fit for characterizing and finding various sorts of faults cannot be exaggerated.

Numerous techniques have been created since the past to find and identify faults in distribution systems with the dispersed era. The strategies can be separated into two classifications, artificial intelligence techniques and conventional. Traveling-wave method [2] and impedancebased method [3] are included in Conventional techniques while Artificial Neural Network (ANN) [4], Support Vector Machine (SVM) [5], Fuzzy Logic [6], Genetic Algorithm (GA) [7], and matching approach [8], are included in artificial 
intelligence techniques. In any case, the fault area utilizing intelligent strategies are challenging since they require preparing information for processing and are time-devouring.

In the distribution system about the fault data, can be acquired at the operation center utilizing end-client data or protective device operation. For fault identification, power utilities have been practicing conventional techniques in the past. The foremost common conventional strategy is based on a visual inspection and trial-and-error switching. For a little zone, a foot patrol is practiced to look at the conceivable fault location whereas, for a bigger scale zone, a vehicle or helicopter is commonly utilized. This methodology of fault location through the visual inspection is appropriate for overhead lines. In any case, for underground cables, the fault line isn't noticeable. Too, the trial and error method could be a manual cycle of changing the hand-off to on/off condition until the circuit breaker trips. It relies upon the organization administrator's fault-finding encounter to find the faulted segment. In any case, this preparation is time-devouring and in the long run, will harm the performance of cables. Due to these issues, different fault area strategies have been presented for the reason of assisting the method of locating issues.

On the other hand, ontologies contain definitions for objects and sorts of objects just as their semantics and relations in a formal, machine-readable way constraining a shared understanding of a few domain areas [9]. In differentiate to a simple taxonomy, which speaks to a hierarchically organized lexicon of non-specific and specialized concepts, an ontology expands this thought by implies of concept relations or limitations in order to upgrade semantic translation. Primary components of ontologies are a chain of command of concepts representing sorts of substances, relations between concepts, limitations on relations, and instances [10].

Several models have been developed to detect or predict failure using AI techniques [15] [16] [17] [18] [19], however, using ontology for this purpose is quite new. According to Ullah et al., [15], The main anomalies arise due to lopsided current, minor breaks in insulators, contact issues, and increments and fall of voltage levels, and other comparative related issues. Their emphasis on recognizing the increment in temperature, which helps in the cure of breakdown even before it happens. Hence, in this article, for non-destructive defect investigation and prevention in power substations, they utilize the computer vision approach and machine learning to identify the issue in the early stages of hardware breakdown by misusing and taking advantage of the infrared thermal pictures.

Another study by Bhattacharya \& Sinha [16] to analyze the fault automatically using machine learning by monitoring the grid and after that within the case of fault decide the type of the fault as and when it happens. To develop an artificially intelligent system that can analyze the grid network data at any given time and decide the health of the network through the utilization of advanced formal models and novel machine learning methods like recurrent neural systems. The scope of this paper emphasized on Predictive Maintenance Tool for Power Substation Faults to evaluate the Distribution Grid configuration since the ontology part is already presented in another paper published by the author [20]. The term "power grid" mentioned in this paper is referring to the portion of the power grid that starts from the substation where the power is stepped-up until the substation where the power is steppeddown.

\section{Proposed Ontology-BAsed Predictive MAINTENANCE TOOL}

As shown in Fig. 1, the process starts when engineers generate several alternative configurations using GCT. The GCT tools contained three types of settings which are Environmental, Operational, and Physical Components. Having generated the configurations, each configuration will be evaluated separately using HSP. In HSP, the duration of simulation of a selected configuration is specified by the user. The next step is to run the simulation, the simulation will receive odd events and communicate with the ontology base to understand the direct impact and indirect impact of each event to the power grid components and subsequently predict failure. The direct impact such as lightening impact to component " $\mathrm{A}$ ", and indirect impact when we have dependent component such as lightening impact to component " $\mathrm{A}$ : and component " $\mathrm{A}$ " impact to component " $\mathrm{B}$ ". During runtime, the simulation can report the status of power grid components, incoming odd events (e.g. rain, wind, lightning), failures, communication activities between the simulation engine and the ontology base, and operational stability level. After the simulation is ended, a maintenance report that shows the failure intensity will be generated. From the failure intensity of each configuration, a decision can be made to choose the best configuration.

Since this paper focuses on the predictive maintenance tool only, the failure prediction model is formulated based on [22]. In this simulation, we use the term odd event which the event that would potentially cause failure. Predicting the failure probability of Component A using Poisson Model, $\mathrm{X}$ is the random event.

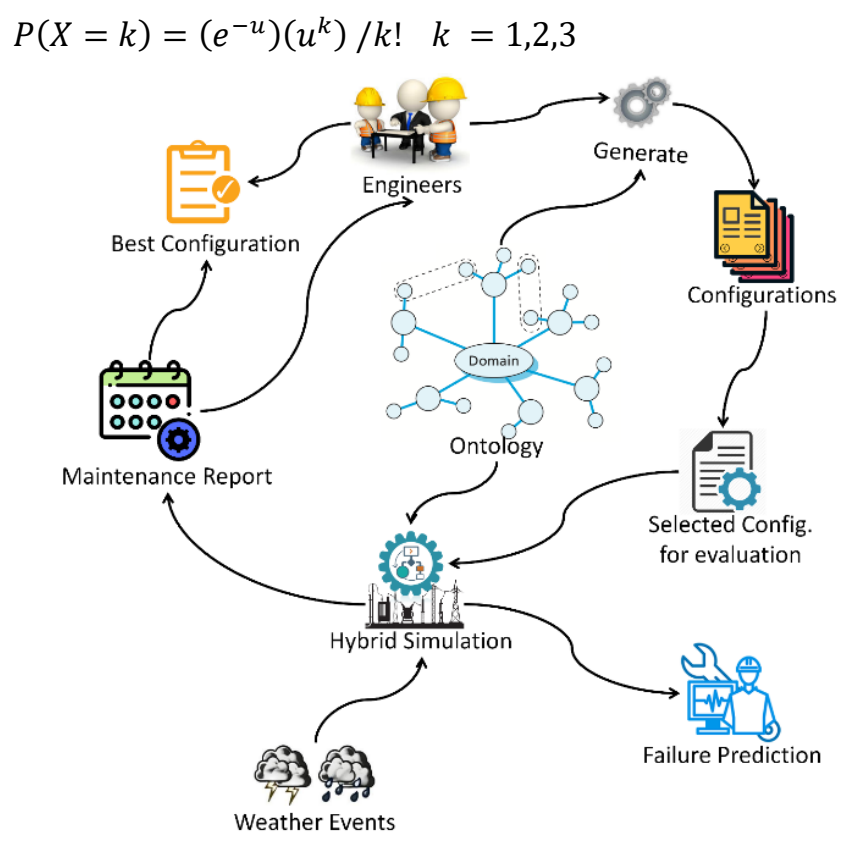

Fig. 1. The Proposed Model. 
Given the length of the period and the average events per time to identify $u$. If no odd event, the life span of a component is,

$u=\frac{\text { events }}{\text { time }} * \mathrm{~T}$

The failure probability per unit time is

$P(X \geq 1)=1-\left(e^{-u}\right)$

If $\mathrm{P}>0.60$ then failure occurred in that component [22]

Thus, the non-failure probability is $1-P$

If an odd event is considered, Lightning is $\mathrm{L}$ and wind speed is $\mathrm{W}$, using the polynomial regression $\mathrm{R}$

$u=\frac{\text { events }}{\text { time }} * \mathrm{~T}$

According to Shuai et a., 2018

$\begin{aligned} R_{L W}=-13.9225 & +3.1331 L-0.0791 L W-0.2645 L^{2} \\ & +0.0727 W^{2}\end{aligned}$

$R_{L W}=\ln (u)$

then

$u=e^{R_{L W}}$

The failure probability based on events inputs per unit time is

$P(X \geq 1)=1-\left(e^{-u}\right)$.

If $\mathrm{P}>0.10$ then failure occurred.

Thus, the non-failure probability is $1-P$.

\section{Substation OnTOLOGY}

The components of the grid identified are categorized based on their usefulness. Based on the data assembled from open sources and recommendations grid specialists as discussed in [20], the team has compiled a set of standard components of the grid. The Power Grid components are isolated into two primary categories: Transmission and Substation. The components, sub-components, properties, and information values are spoken to by diverse colors to appear the relationship of these components. Categorizing the power grid components will too ease the representation of the components data in an Ontology-based environment.

The substation data is represented in ontology utilizing the Protégé computer program. Based on the discussion with the power grid professional, it is suggested that the study should be conducted on the distribution substation. This can be since the number of substation components is relatively lesser and the experience mastered during the information portrayal cycle will facilitate the future portrayal processes. Other than this, beginning with a more modest scale information representation is continuously empowering. The master too focused that, among power grid components, substations' components are more inclined to expensive failure compared to those transmission components, and hence the group has more practical information to assess the success of the portrayal. The representation begins with the choice of ontology improvement stage. For this project, Protégé was chosen as the development stage. Fig. 2 shows a sample of the visualization extracted from the Protégé development platform that shows the representation of substation's components using OWL in protégé. This portrayal is based on the power grid key components chart. The connection between the most components, sub-components, and the component's properties are clearly shown. Protégé too permits the client to present the relationship of the components in a diagrammatic arrangement as shown in Fig. 2.

The configuration and simulation model is developed by using the software listed in Table I. This model is accessing the data stored in the Ontology storage to perform the simulation on each component of the substation. Based on the simulation, the model is able to predict the possibility of component failure based on the geometrical and environmental factors. The model was tested using the historical data and proved that the model can alert the user with the possibility of the components' failure.

The collected data used in developing the tool are presented in Tables II to VIII.

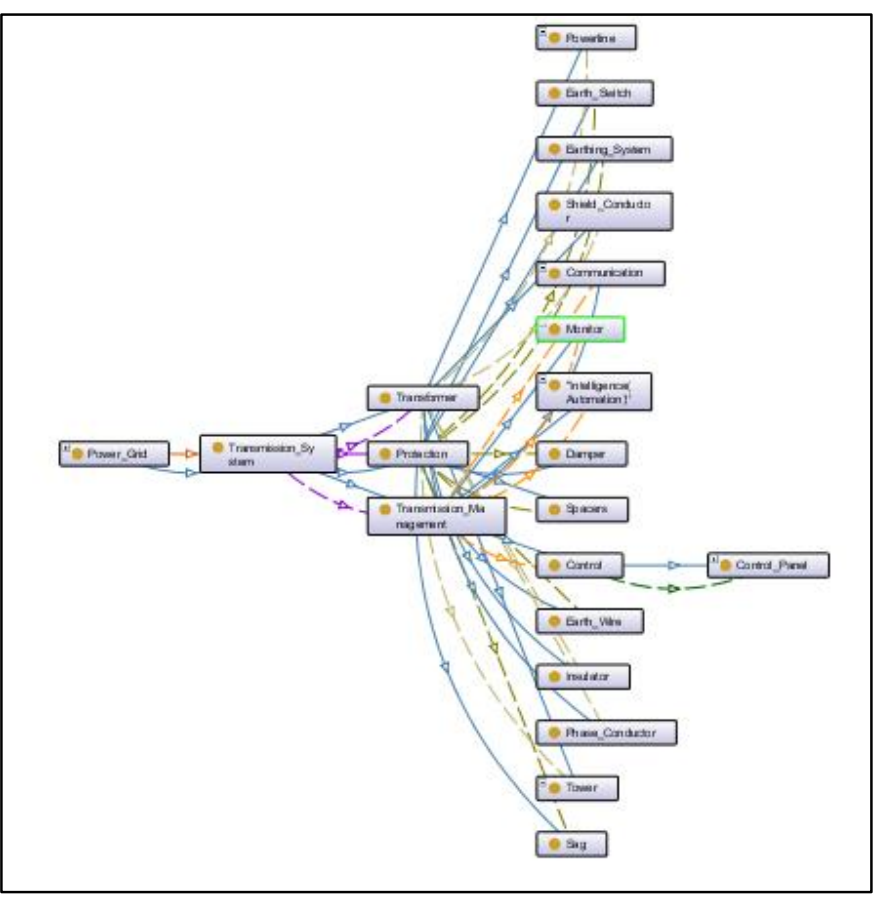

Fig. 2. Diagrammatic Representations of Substation Components.

TABLE I. SOFTWARE USED IN THE DEVELOPMENT

\begin{tabular}{|l|l|}
\hline Development & Software used \\
\hline 3D modeling & Blender \\
\hline 3D engine & Unity 3D \\
\hline Web application & MS SQL \\
\hline Ontology & Apache Jena, Fuseki-Triplet Database Store \\
\hline Server & Asp.net \\
\hline Client & Angularjs \\
\hline
\end{tabular}


TABLE II. POWERLINE

\begin{tabular}{|c|c|c|c|c|c|c|}
\hline \multirow{2}{*}{\multicolumn{2}{|c|}{ Components }} & \multicolumn{5}{|l|}{ Specifications } \\
\hline & & \multirow{3}{*}{$\begin{array}{l}\text { Material } \\
\text { - Aluminum } \\
\text { - Alloy } \\
\text { - Steel } \\
\text { - Copper }\end{array}$} & \multirow{2}{*}{$\begin{array}{c}\text { Voltage } \\
765 \mathrm{kV}\end{array}$} & \multirow{2}{*}{$\begin{array}{l}\text { Phase } \\
\text { Three-phase }\end{array}$} & \multirow{2}{*}{$\begin{array}{l}\text { distance } \\
3,800 \mathrm{~km}\end{array}$} & \multirow[t]{2}{*}{ Type } \\
\hline \multirow{5}{*}{ Powerline } & Overhead AC & & & & & \\
\hline & Overhead DC & & $800 \mathrm{kV}$ & Three-phase & $4,800 \mathrm{~km}$ & \\
\hline & Underground AC & Copper & $\begin{array}{l}>50 \mathrm{kV} \text { and } 10 \mathrm{kV}- \\
33 \mathrm{kV}\end{array}$ & & $80 \mathrm{~km}$ & \\
\hline & Underground DC & & & & & \\
\hline & Submarine & $\begin{array}{l}\text { - Copper } \\
\text { - Fiber optic } \\
\text { - Aluminum }\end{array}$ & $\begin{array}{l}\text { - } \mathrm{Ac}-30-5 \mathrm{~d} 5 \mathrm{kV} \\
\text { - } \mathrm{Dc}-250- \\
\quad 600 \mathrm{kV}\end{array}$ & & & $\begin{array}{l}\text { - Oil linked } \\
\text { - Cross-linked } \\
\text { polyethylene }\end{array}$ \\
\hline
\end{tabular}

TABLE III. TRANSFORMER FOUNDATION

\begin{tabular}{|c|c|c|c|c|c|}
\hline \multirow{2}{*}{\multicolumn{3}{|c|}{ Components }} & \multicolumn{3}{|l|}{ Specifications } \\
\hline & & & \multirow[b]{2}{*}{$\begin{array}{l}\text { Types } \\
\text { - Steel grillage } \\
\text { - Concrete spread footing } \\
\text { - Concrete auger/caisson } \\
\text { - Pile } \\
\text { - Rock } \\
\text { - Novel } \\
\text { - Undercut pyramid } \\
\text { - Concrete auger }\end{array}$} & \multirow[b]{2}{*}{$\begin{array}{l}\text { Foundation Type } \\
\text { - Igneous } \\
\text { - Sedimentary rock } \\
\text { - Metamorphic soil } \\
\text { - Sand/gravel } \\
\text { - Cohesive soil }\end{array}$} & \multirow{2}{*}{$\begin{array}{l}\text { Requirement } \\
\\
\text { - 1yard cement } \\
\text { - 30in x 30in x 6ft (per } \\
\text { stub) }\end{array}$} \\
\hline Transformer & Tower & Foundation & & & \\
\hline
\end{tabular}

TABLE IV. TRANSFORMER CROSS-ARM

\begin{tabular}{|c|c|c|c|c|c|c|c|c|c|c|}
\hline \multirow{2}{*}{\multicolumn{3}{|c|}{ Components }} & \multicolumn{8}{|l|}{ Specifications } \\
\hline & & & Materials & Braces type & Bolt size & Types & Shape & Bracket type & Voltage & Design \\
\hline Transformer & Tower & Cross-arm & $\begin{array}{l}\text { - Wood } \\
\text { - Steel } \\
\text { - Fiber glass } \\
\text { - Galvanized } \\
\text { - steel } \\
\text { - timber }\end{array}$ & 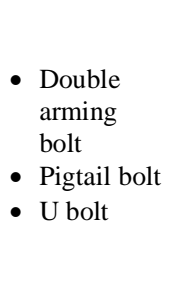 & $\begin{array}{l}2 \mathrm{~mm} \\
\text { gauge } \\
\text { diameter }\end{array}$ & $\begin{array}{l}\text { - Pole top } \\
\text { - Two arm } \\
\text { - Single } \\
\text { arm } \\
\text { - Line arm } \\
\text { - Side arm }\end{array}$ & $\begin{array}{l}\text { 'V' } \\
\text { design }\end{array}$ & $\begin{array}{l}\text { - Short } \\
\text { aluminum } \\
\text { - Short } \\
\text { stainless steel } \\
\text { - Aluminum } \\
\text { - Longest } \\
\text { stainless steel } \\
\text { - Longest } \\
\text { aluminum }\end{array}$ & $\begin{array}{l}\text { - } \mathrm{Ac}-35 \\
- \\
1,000 \mathrm{k} \\
\mathrm{V} / 110 \\
- \\
1,000 \mathrm{k} \\
\mathrm{V} \\
\text { - } \mathrm{Dc}- \\
800 \mathrm{kV}\end{array}$ & $\begin{array}{ll}\text { - } & \text { Single } \\
\text { post } \\
\text { - Single } \\
\text { post } \\
\text { stayed } \\
\text { - Double } \\
\text { post } \\
\text { stayed }\end{array}$ \\
\hline
\end{tabular}

TABLE V. TRANSFORMER STRUCTURE

\begin{tabular}{|c|c|c|c|c|c|c|c|c|c|c|}
\hline \multirow{2}{*}{\multicolumn{4}{|c|}{ Components }} & \multicolumn{7}{|c|}{ Specifications } \\
\hline & & & & \multirow{2}{*}{$\begin{array}{l}\text { Voltage } \\
\\
\text { - } 220 \mathrm{kV} \\
\text { - } 500 \mathrm{kV}\end{array}$} & \multirow{2}{*}{$\begin{array}{l}\text { Height } \\
\text { - } 110-200 \mathrm{ft} \\
\text { - } 150-515 \mathrm{ft} \\
\text { - } 80-200 \mathrm{ft}\end{array}$} & \multirow{2}{*}{$\begin{array}{l}\text { Angles } \\
\text { - } \mathrm{L} \\
\text { beam } \\
\text { - } \mathrm{T} \\
\text { beam }\end{array}$} & \multirow{2}{*}{$\begin{array}{ll}\text { Structure } \\
\text { - } & \text { Bolt } \\
& \text { connections } \\
\text { - } & \text { Main structural } \\
& \text { members } \\
\text { - } & \text { Bracing system }\end{array}$} & \multirow{3}{*}{$\begin{array}{l}\text { Circuit } \\
\\
\text { - Double } \\
\text { - Single }\end{array}$} & \multirow{2}{*}{ width } & \multirow{2}{*}{ material } \\
\hline \multirow{6}{*}{ Transformer } & \multirow{6}{*}{ Tower } & \multirow{6}{*}{ Structure } & $\begin{array}{l}\text { Lattice steel } \\
\text { tower }\end{array}$ & & & & & & & \\
\hline & & & $\begin{array}{l}\text { Tubular steel } \\
\text { tower }\end{array}$ & $\begin{array}{l}\text { - } 110 \mathrm{kV} / \\
500 \mathrm{kV} \\
\text { - } 220 \mathrm{kV}\end{array}$ & $\begin{array}{l}\text { - } 70-200 \mathrm{ft} \\
\text { - } 55-200 \mathrm{ft}\end{array}$ & & & & & $\begin{array}{l}\text { - Steel } \\
\text { - Steel tube } \\
\text { pylons }\end{array}$ \\
\hline & & & h-frame & $230 \mathrm{kV}$ & $60-90 \mathrm{ft}$ & & & & $\begin{array}{l}100- \\
160 \mathrm{ft}\end{array}$ & wood \\
\hline & & & Monopole & $\begin{array}{l}\text { Up to } \\
400 \mathrm{kV}\end{array}$ & $40 \mathrm{~m}$ & & & & $1.5-2 \mathrm{~m}$ & aluminum \\
\hline & & & Underground & $345 \mathrm{kV}$ & & & & & $40-65 \mathrm{~m}$ & \\
\hline & & & Turning & & & & & & & \\
\hline
\end{tabular}


TABLE VI. SUBSTATION TRANSFORMER

\begin{tabular}{|c|c|c|c|c|c|c|}
\hline \multirow{2}{*}{\multicolumn{2}{|c|}{ Components }} & \multicolumn{5}{|c|}{ Specifications } \\
\hline & & Weight & Type & Height & Shape & Material \\
\hline \multirow{4}{*}{$\begin{array}{l}\text { Substation } \\
\text { transformer }\end{array}$} & Buchholz relay & $\begin{array}{l}\text { - } 3.9 \mathrm{~kg} \\
\text { - } 2,31 \mathrm{~kg}\end{array}$ & $\begin{array}{l}\text { - } \mathrm{BS} 25 \\
\text { - } \mathrm{BS} 50 \\
\text { - } \mathrm{BS} 80\end{array}$ & & & \\
\hline & Oil level indicator & & & & & \\
\hline & Breather & $5 \mathrm{~kg}$ & Silicon gel & $<1200 \mathrm{~mm}$ & & \\
\hline & Main tank & 100tons & & & Bell & $\begin{array}{l}\text { - Plate steel (base) } \\
\text { - Sand blasted } \\
\text { - Rus inhibiting primer }\end{array}$ \\
\hline
\end{tabular}

TABLE VII. SUBSTATION TRANSFORMER PRIMARY AND SECONDARY WINDING

\begin{tabular}{|c|c|c|c|c|c|c|}
\hline \multirow{2}{*}{\multicolumn{2}{|c|}{ Components }} & \multicolumn{5}{|c|}{ Specifications } \\
\hline & & Voltage & Material & No. Of turns & Size gauge wire & Height \\
\hline \multirow{2}{*}{$\begin{array}{l}\text { Substation } \\
\text { transformer }\end{array}$} & Primary winding & $2,400-13,800 \mathrm{kV}$ & \multirow{2}{*}{$\begin{array}{l}\text { - Aluminum } \\
\text { - Copper }\end{array}$} & *many & $*_{\text {small }}$ & \multirow{2}{*}{$10 \mathrm{~cm}$} \\
\hline & Secondary winding & $<600 \mathrm{kV}$ & & $*_{\text {few }}$ & *large & \\
\hline
\end{tabular}

TABLE VIII. SUBSTATION TRANSFORMER

\begin{tabular}{|c|c|c|c|c|c|c|}
\hline \multirow{2}{*}{\multicolumn{2}{|c|}{ Components }} & \multicolumn{5}{|l|}{ Specifications } \\
\hline & & Type & Material & Voltage & Size & Phase \\
\hline \multirow{4}{*}{$\begin{array}{l}\text { Substation } \\
\text { Transformer }\end{array}$} & Radiator & $\begin{array}{l}\text { - Air natural/self-cooled } \\
\text { - Air blast } \\
\text { - Oil natural air natural } \\
\text { - Oil natural air forced } \\
\text { - Oil forced air forced } \\
\text { - Oil forced water forced }\end{array}$ & & & & \\
\hline & LT \& HT Bushes & $\begin{array}{ll}\text { - Normal } \\
\text { - } \mathrm{A} / \mathrm{F} \\
\text { - } \mathrm{LV} \\
\end{array}$ & $\begin{array}{l}\text { - Paper } \\
\text { - Porcelain } \\
\text { - Resin } \\
\end{array}$ & $\begin{array}{ll} & 12-36 \mathrm{kV} \\
\text { - } & 0.66-52 \mathrm{kV} \\
\text { - } & 1.1-3.6 \mathrm{kV} \\
\end{array}$ & & \\
\hline & Tap changer & $\begin{array}{l}\text { - No load } \\
\text { - On load } \\
\text { - Mechanical }\end{array}$ & & Vary & & \\
\hline & Air release plug & & M.S. & & $15 \mathrm{~mm}$ & $\begin{array}{l}\text { - Single phase } \\
\text { - Three-phase }\end{array}$ \\
\hline
\end{tabular}

\section{Simulation AND Results}

Fig. 3 shows the landing page for the application. From here the user can navigate to configuration creation page or run a simulation.

As shown in Fig. 3, the user can either enter the simulation from the shortcut in the landing page or from the sidebar menu. There are three steps the user needs to complete before running the simulation, (i) Step 1 - select configuration, (ii) Step 2 enter the simulation runtime (number of days). Step $3-$ confirm the selected settings. Fig. 4 shows the list of created configurations that can be selected for the simulation.

Fig. 5 shows the field where the user must enter the simulation runtime, the number of days the simulation will run.

Fig. 6 shows all the settings, a user has selected; the user expects to confirm these settings before running the simulation.

Fig. 7 shows the entire power grid setup. For this ontology demonstration, we are only focusing on the substation transformer near the housing area. Notice that the menus on the side and top are disabled to prevent the user from accidentally exit the simulation. Users can exit the simulation by clicking on the 'Exit to dashboard' button on the top right corner.

In order to enter the substation transformer simulation, the user has to click on the substation highlighted in Fig. 8.

Fig. 9 shows the substation transformer simulation setup. When the user entered the substation transformer simulation, the simulation will be immediately started. The green lights over the transformer, represent each component, user can hover over it to see the component name as shown in Fig. 10.

Fig. 11 shows the activities in the simulation. The activity is shown by each day followed by the current environmental event if any. As each day pass the simulation will consult ontology bypassing the current environment event, then the ontology will reply back the substation components that might be affected by this environment event. 


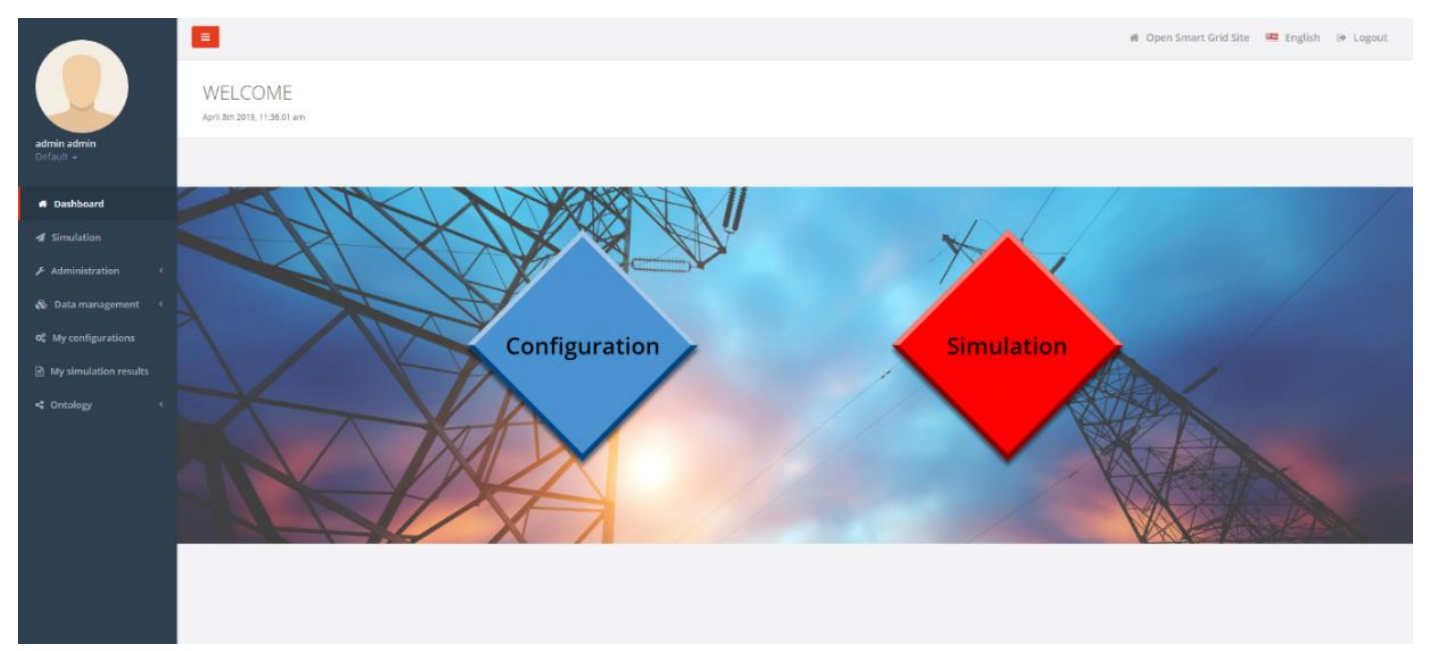

Fig. 3. Landing Page.

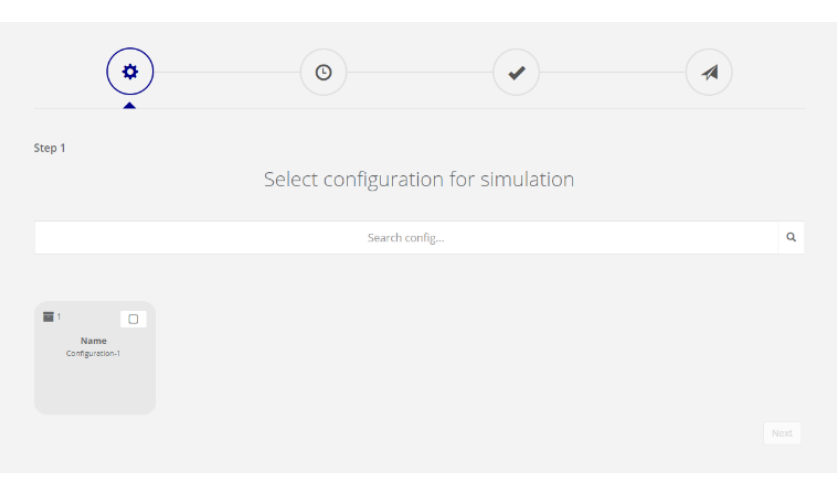

Fig. 4. Select a Configuration for Testing.

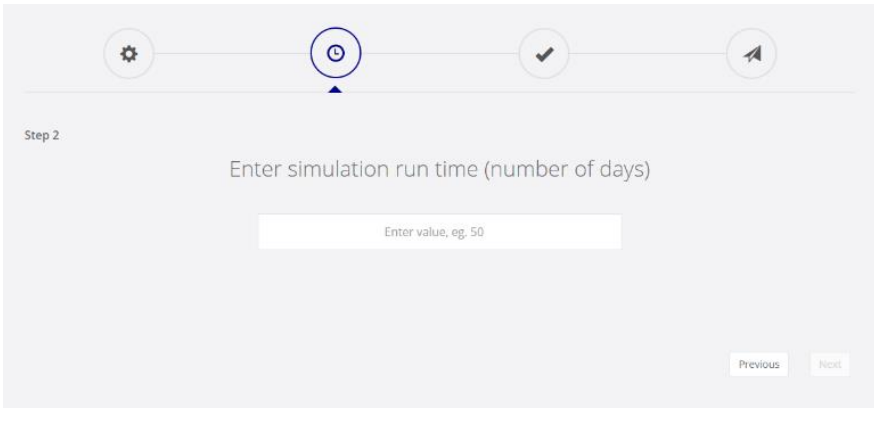

Fig. 5. Enter the Simulation Runtime.

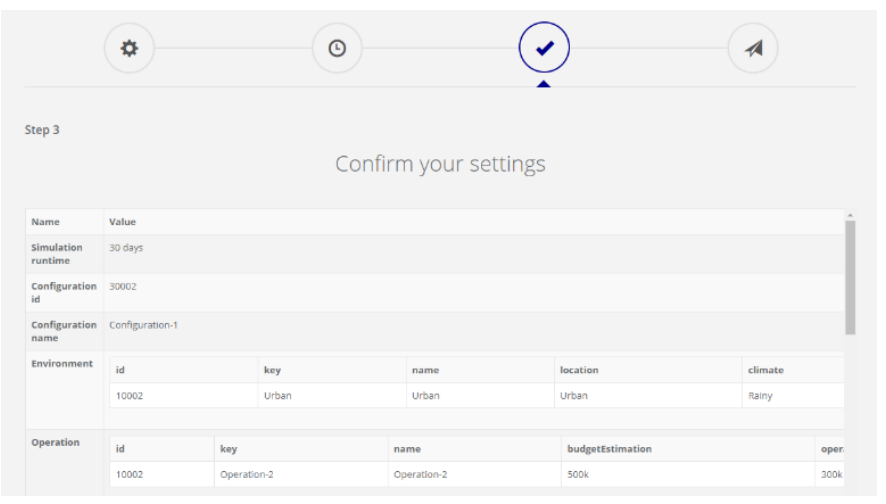

Fig. 6. View All Settings.

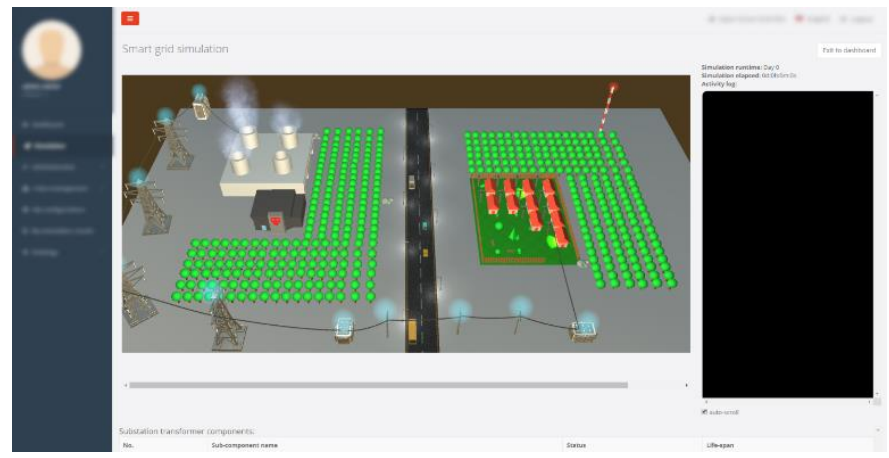

Fig. 7. The Entire Power Grid Setup.

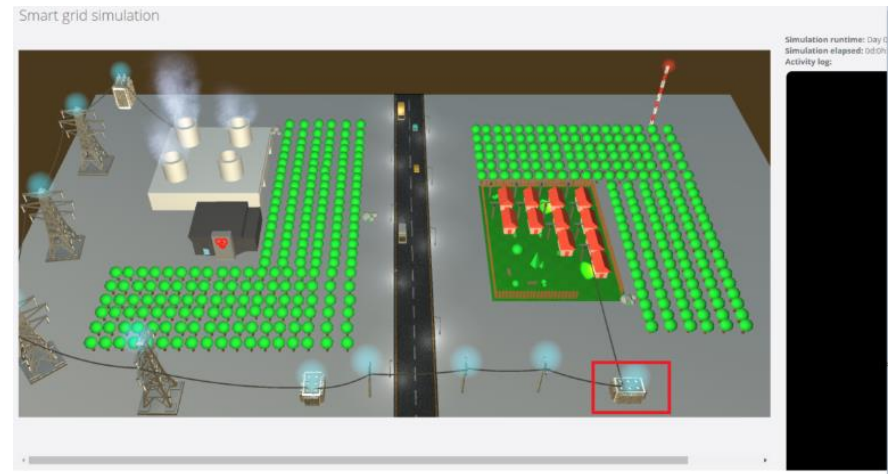

Fig. 8. Substation Transformer.

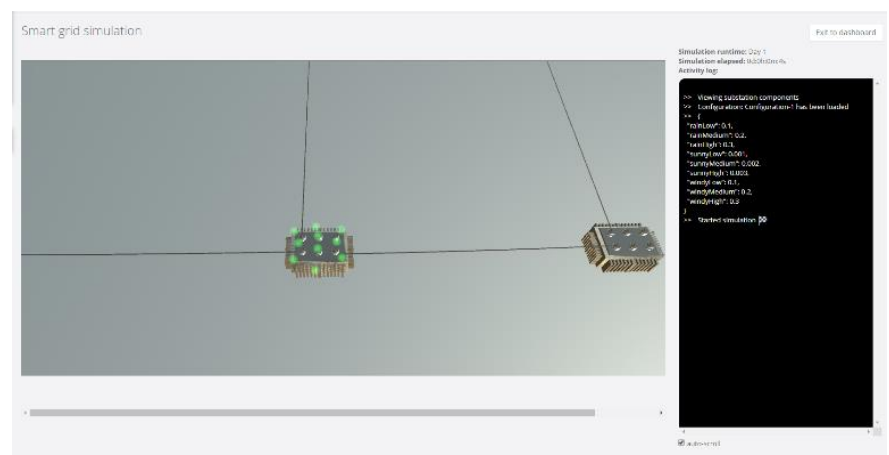

Fig. 9. The Substation Transformer Simulation. 


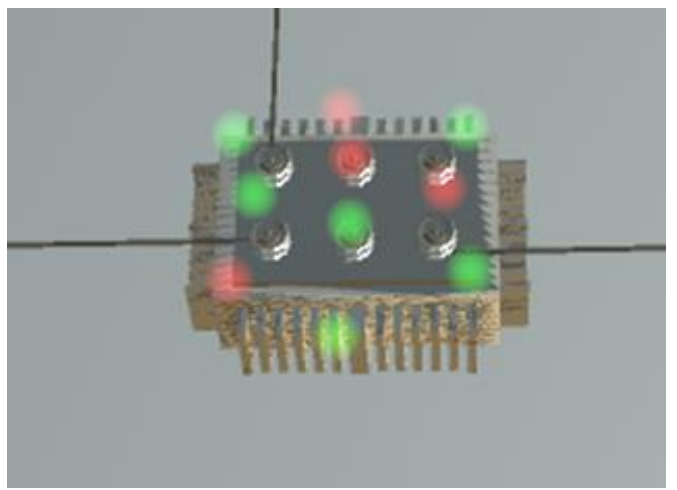

Fig. 10. Shows the Components that Failed/Effected by the Environment Event (Green - Active, Yellow - Predicted Failure, Red - Failure).

Fig. 12 shows the status of the components in more detail. Once the simulation has ended, the user can get the simulation report by going to the report page as shown in Fig. 20.
The simulation tool can analyze the simulation data and display reports of critical information. One of them presenting the failure occurrence and its probability using the Poisson model. As shown in Fig. 13, the probability of the highest probability of failure occurrence in the substation is 63 times with the simulation period. Fig. 14 shows the link to simulation report page. In order to view the report, the user can click on the 'Action' button next to the listed report and see the option to view the report. 'View report' will show a brief readable report, 'View report data' will show the complete data logged in the simulation in raw form. Fig. 14 shows the simulation report. User can also download this report as PDF document by clicking on the 'Download' button on top of the report.

Fig. 15 shows the predicted failure in which day based on the analysis of odd events, based on [22], when the probability exceeds 0.05 , the failure would happen.

Fig. 16 Status of the substation components from Day 2 to Day 48 using the Poisson regression model.

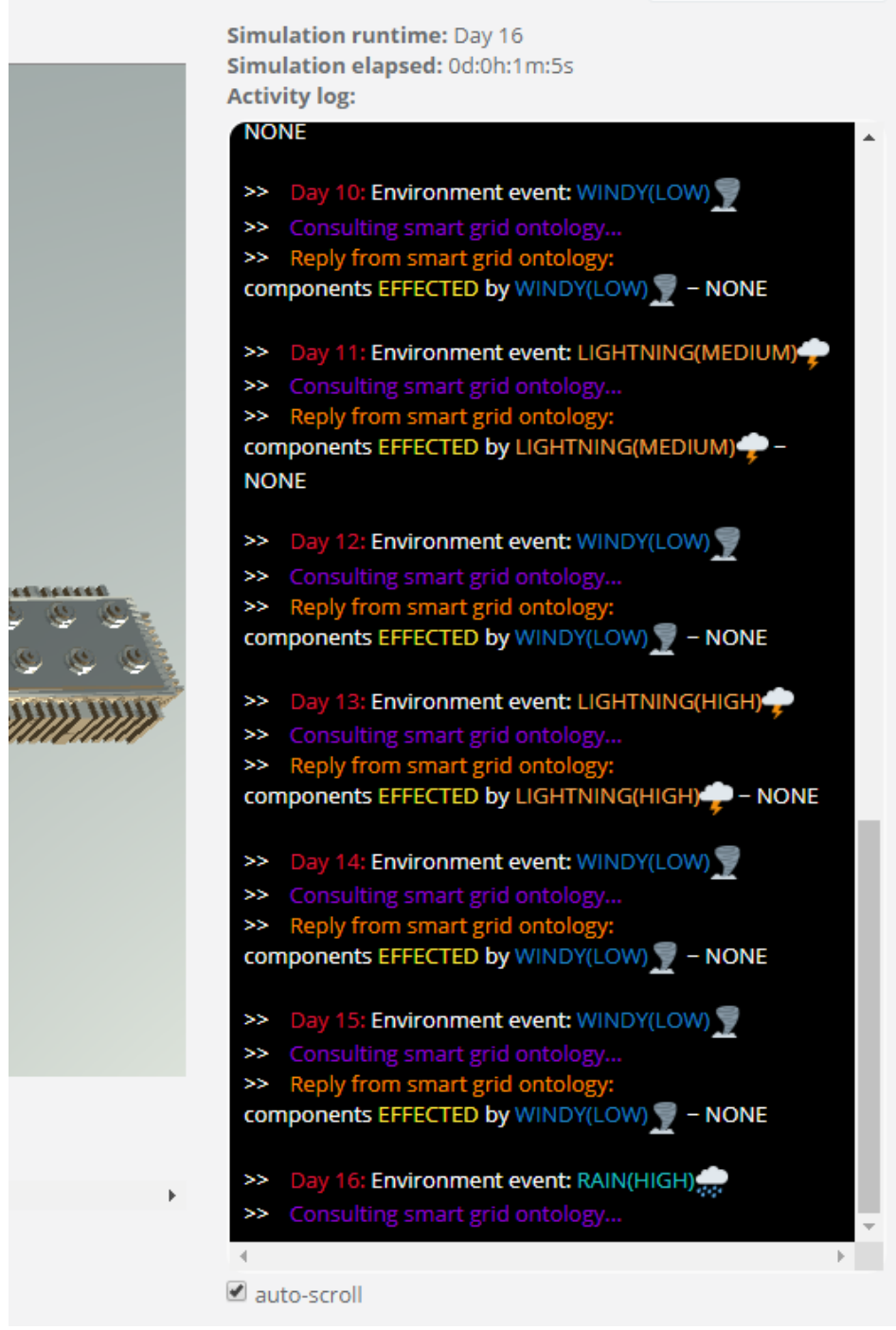

Fig. 11. The Activities in the Simulation. 


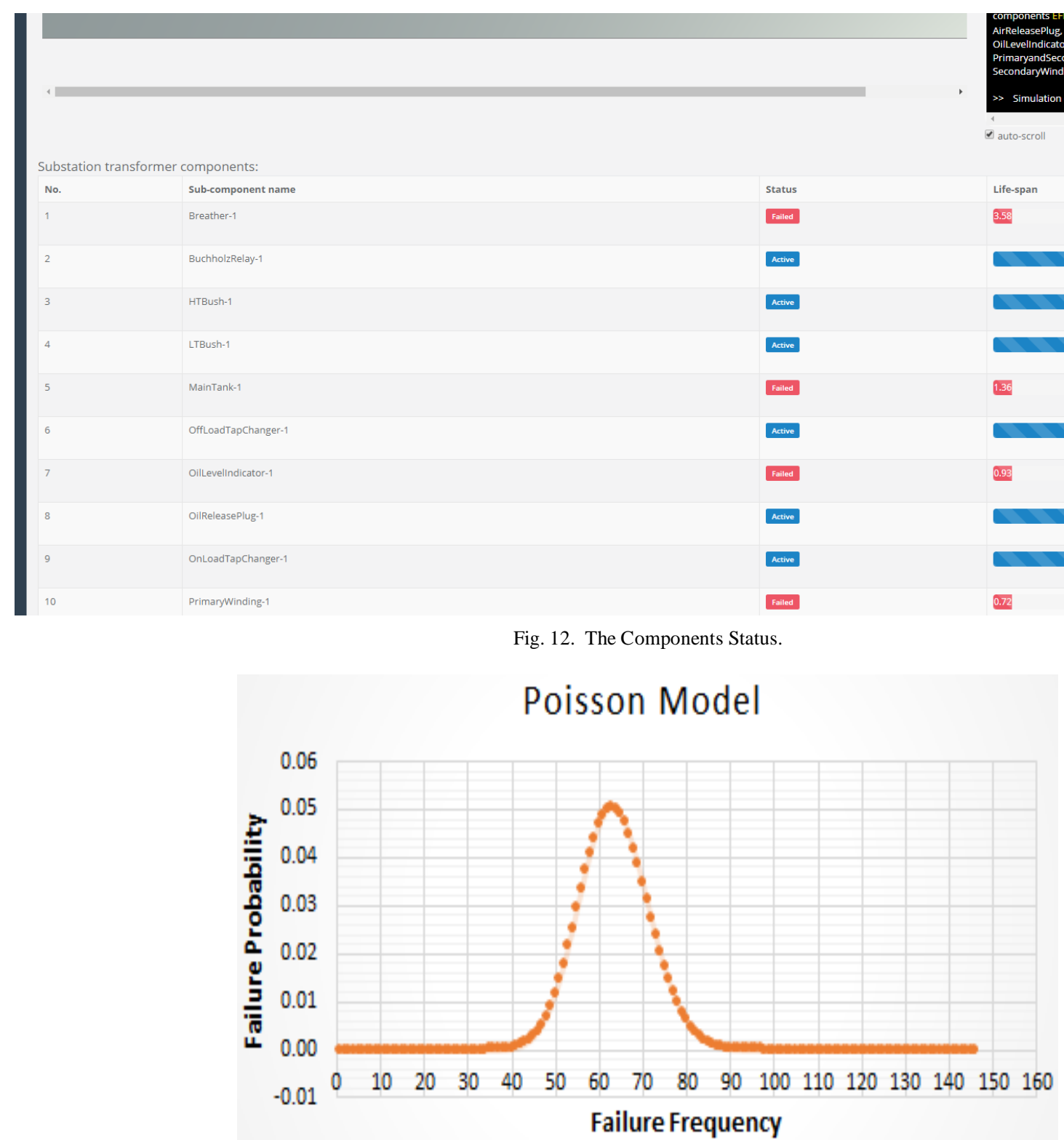

Fig. 13. Failure Occurrence Probability. 


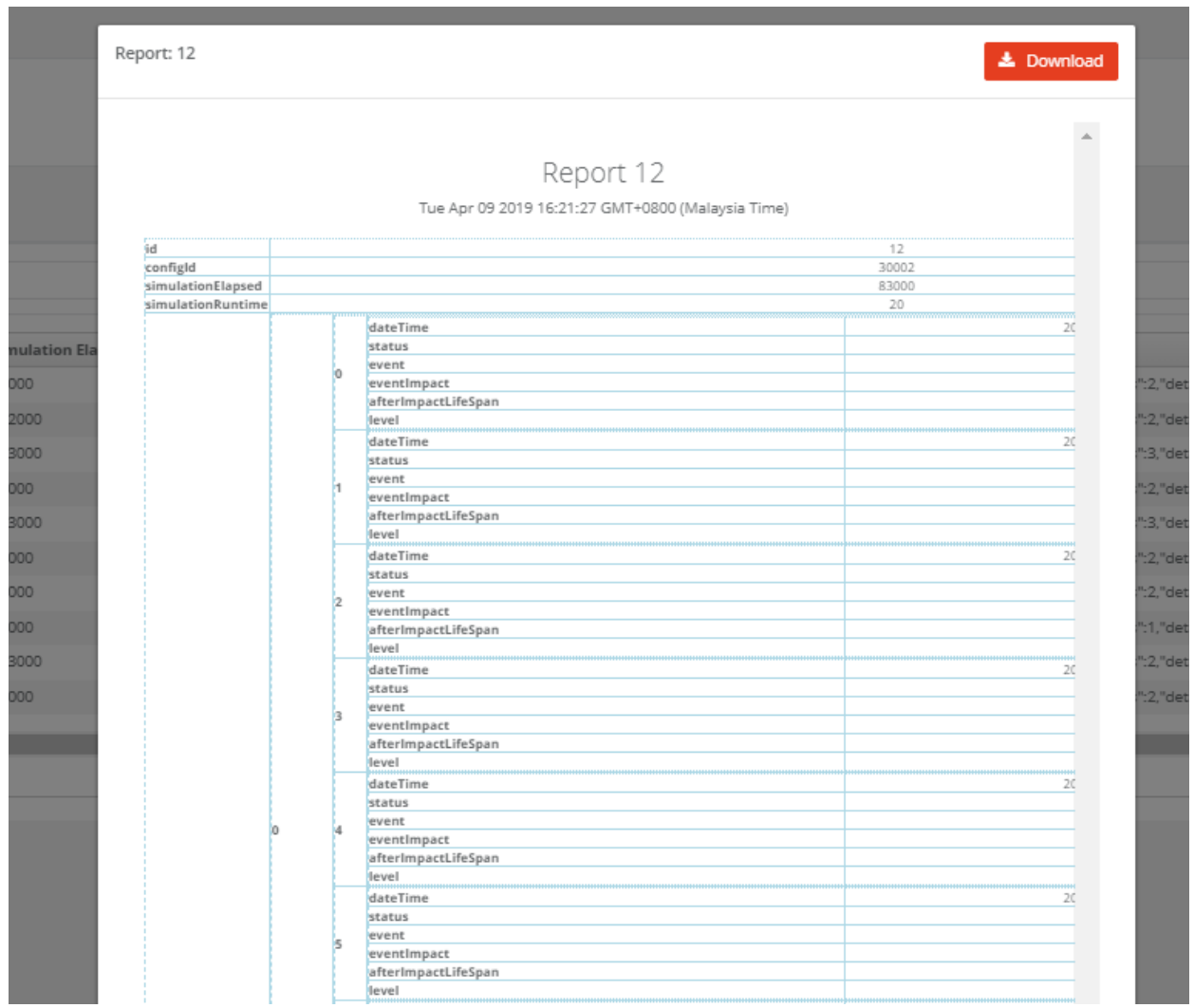

Fig. 14. The Simulation Report.

Failure based event model

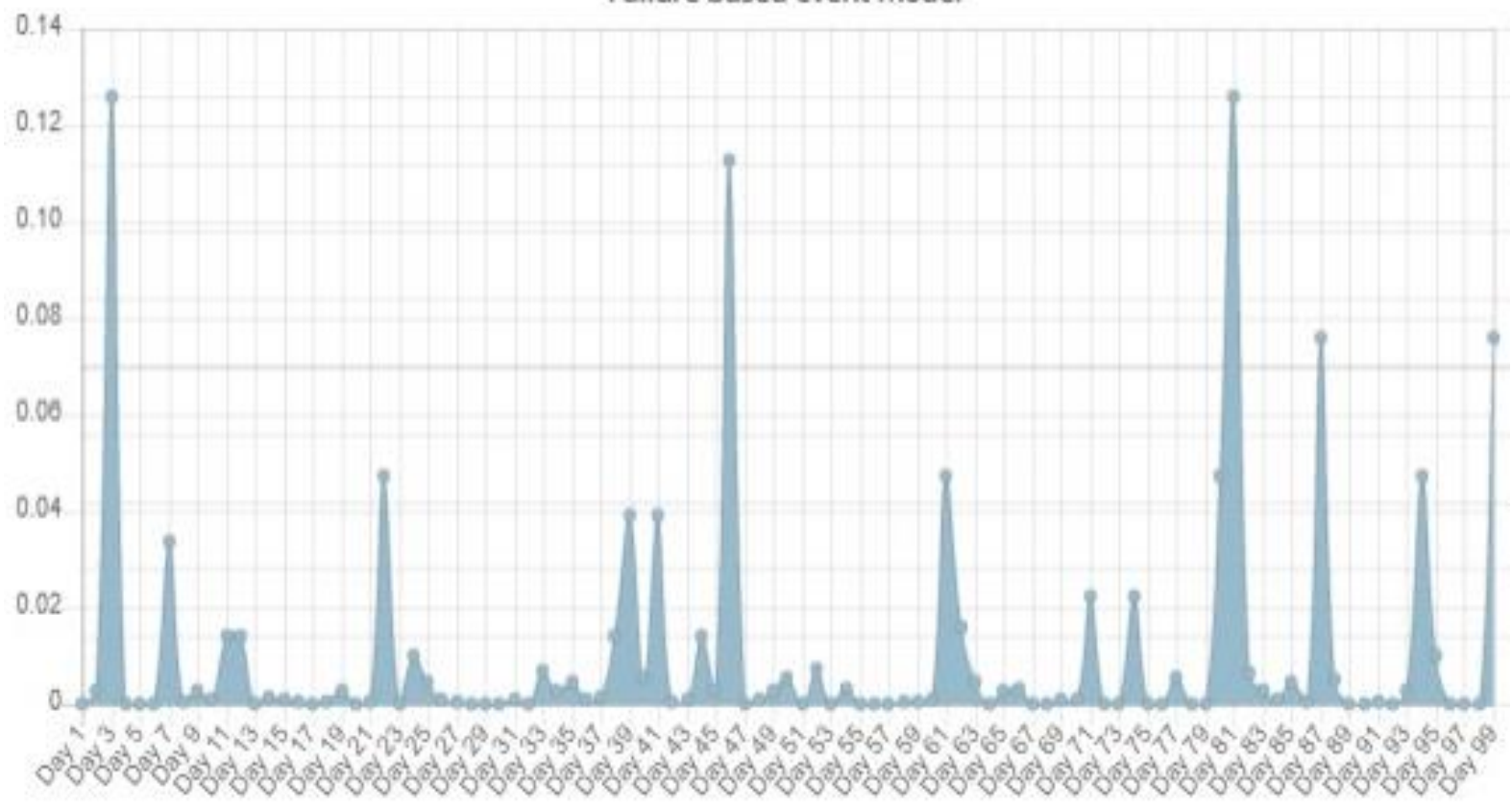

Fig. 15. Failure Prediction. 


\section{Poisson regression model}

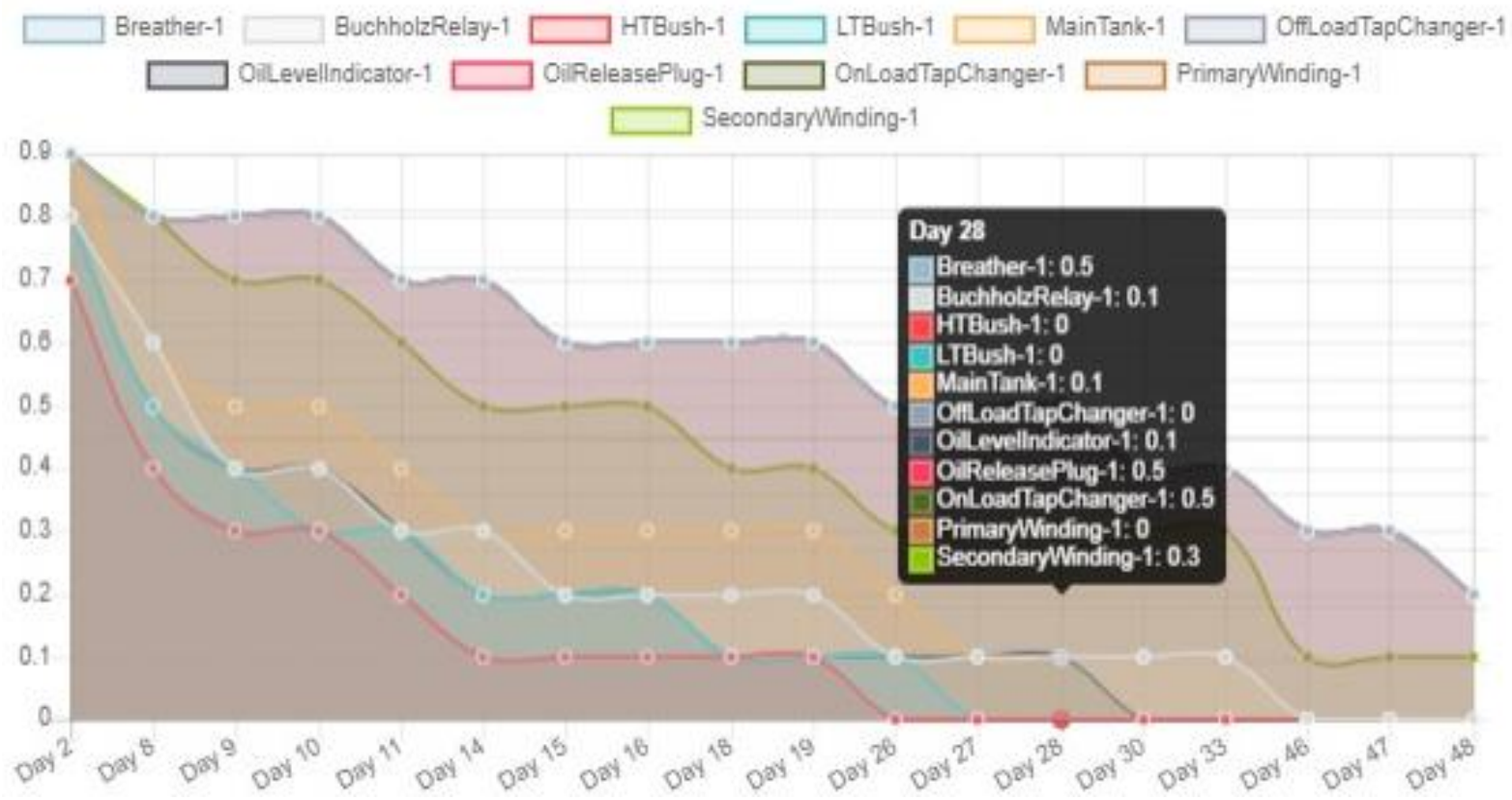

Fig. 16. Status of Substation Components.

\section{CONCLUSION}

In this paper, a simulation tool to predict failure and subsequently generate a maintenance report for a particular power substation configuration is presented. The proposed system consists of three components. The developed evaluation system consists of three main components which are Configuration Generator Tool (GCT), Failure Prediction Model (FDM), and Hybrid Simulation Platform (HSP). The GCT was used to generate alternative configurations and developed using Web Ontology Language (OWL). While the HSP is developed using several simulations and ontology-based tools such as HTML5, Javascript, Apache Jena, Unity Engine, C\# Programming Language, Visual Studio 2017 IDE, and Blender 3D modeling. The FDM is developed based on the impact and relationship of weather factors (e.g. rain, wind, lightning) to power grid components and the impact of a failed component to other components. The results showed a powerful tool to predict failure with 3D simulation, however, further validation needs to be conducted to tune the prediction model using concrete instances and this is left for future work.

\section{ACKNOWLEDGMENT}

This project is sponsored by Universiti Tenaga Nasional (UNITEN) under the Bold Research Grant Scheme No.RJO10517844/010.

\section{REFERENCES}

[1] Shafiullah, M., Abido, M. A., \& Abdel-Fattah, T. (2018). Distribution Grids Fault Location employing ST based Optimized Machine Learning Approach. Energies, 11(9), 2328.

[2] Lee H, Mousa AM. GPS travelling wave fault locator systems: investigation into the anomalous measurements related to lightning strikes. Power Deliv IEEE Trans on 1996;11:1214-23.

[3] Sant MT, Paithankar YG. Online digital fault locator for overhead transmission line. Electr Eng Proc Inst of 1979;126:1181-5.
[4] Purushothama GK, et al. ANN applications in fault locators. Int J Electr Power Energy Syst 2001;23:491-506, [8//].

[5] Cortes C, Vapnik V. Support-vector networks. Mach Learn 1995;20:273-97, [1995/09/01].

[6] Pradhan AK, et al. Higher order statistics-fuzzy integrated scheme for fault classification of a series-compensated transmission line. IEEE Trans Power Deliv 2004;19:891-3.

[7] Bedekar PP, et al. Fault section estimation in power system using Hebb's rule and continuous genetic algorithm. Int J Electr Power Energy Syst 2011;33:457-65, [3// ].

[8] Mokhlis H, Li HY. Fault location estimation for distribution system using simulated voltage sags data. In: Proceedings of the universities power engineering conference, 2007. UPEC 2007. 42nd International, 2007 , p. $242-7$.

[9] Uschold, M., \& Gruninger, M. (1996). Ontologies: Principles, methods and applications. The knowledge engineering review, 11(2), 93-136.

[10] Schachinger, D., Kastner, W., \& Gaida, S. (2016, April). Ontologybased abstraction layer for smart grid interaction in building energy management systems. In 2016 IEEE International Energy Conference (ENERGYCON) (pp. 1-6). IEEE.

[11] Mahmoud, M. A., Maseleno, A., Tang, A. Y., Lim, F. C., Kasim, H. B., \& Yong, C. (2019, September). Analysis of the Publications on Ontology-Based Smart Grid Applications: A Bird's Eye View. In International Conference on Applied Computing to Support Industry: Innovation and Technology (pp. 491-502). Springer, Cham.

[12] Law, N. L. L. M. F., Mahmoud, M. A., Tang, A. Y. C., Lim, F. C., Kasim, H., Othman, M., \& Yong, C. (2019). A review of ontology development aspects. International Journal of Advanced Computer Science and Applications, 10(7), 290-298.

[13] Mahmoud, M. A., Tang, A. Y., Maseleno, A., Lim, F. C., Kasim, H., \& Yong, C. (2019, September). Towards the Development of a Smart Energy Grid. In International Conference of Reliable Information and Communication Technology (pp. 673-682). Springer, Cham

[14] Maseleno, A., Hashim, W., Tang, A. Y., Mahmoud, M. A., \& Othman, M. (2020). A Brief Understanding on Smart Grid Technology. Journal of Computational and Theoretical Nanoscience, 17(6), 2866-2868.

[15] Ullah, I., Yang, F., Khan, R., Liu, L., Yang, H., Gao, B., \& Sun, K. (2017). Predictive maintenance of power substation equipment by infrared thermography using a machine-learning approach. Energies, 10(12), 1987. 
[16] Bhattacharya, B., \& Sinha, A. (2017, November). Intelligent fault analysis in electrical power grids. In 2017 IEEE 29th International Conference on Tools with Artificial Intelligence (ICTAI) (pp. 985-990). IEEE.

[17] Zhang, S., Wang, Y., Liu, M., \& Bao, Z. (2017). Data-based line trip fault prediction in power systems using LSTM networks and SVM. IEEE Access, 6, 7675-7686.

[18] Novoselnik, B., Bolfek, M., Bošković, M., \& Baotić, M. (2017) Electrical power distribution system reconfiguration: Case study of a real-life grid in croatia. IFAC-PapersOnLine, 50(1), 61-66.

[19] Lawrence, T. M., Watson, R. T., Boudreau, M. C., \& Mohammadpour, J. (2017). Data flow requirements for integrating smart buildings and a smart grid through model predictive control. Procedia engineering, 180, 1402-1412.

[20] Tang, A. Y. C., Mahmoud, M. A., Lim, F. C., Kasim, H. (2020) Description for Smart Grid: Towards the Ontological Approach, The 8th International Conference on Information Technology and Multimedia (ICIM $\mu$ 2020).

[21] Tang, A. Y. C., Mahmoud, M. A., Lim, F. C., Kasim, H. (2020) A review of Smart Grid Technology, Components, and Implementation, The 8th International Conference on Information Technology and Multimedia (ICIM $\mu$ 2020).
[22] Yang, S., Zhou, W., Zhu, S., Wang, L., Ye, L., Xia, X., \& Li, H. (2019). Failure probability estimation of overhead transmission lines considering the spatial and temporal variation in severe weather. Journal of Modern Power Systems and Clean Energy, 7(1), 131-138.

[23] Mahmoud MA., Ramli R., Azman F, and Grace J. (2018). A Development Methodology Framework of Smart Manufacturing Systems (Industry 4.0), MySEC 2018.

[24] Ahmed M, Ahmad MS, Yusoff MZ. Modeling agent-based collaborative process. InInternational Conference on Computational Collective Intelligence 2010 Nov 10 (pp. 296-305). Springer, Berlin, Heidelberg.

[25] Mahmoud, M., Ahmad, M. S., Mostafa, S., \& Subramainan, L. (2020). How New Individuals Behave in a Heterogeneous Community: A Computational Approach to Norm Assimilation Using Agent-Based Systems. Journal of Systems Science and Complexity, 33(4), 849-881.

[26] Mahmoud MA, Ahmad MS, Yusoff MZ. A norm assimilation approach for multi-agent systems in heterogeneous communities. InAsian Conference on Intelligent Information and Database Systems 2016 Mar 14 (pp. 354-363). Springer, Berlin, Heidelberg.

[27] Mahmoud MA, Ahmad MS, Yusoff MZ. Development and implementation of a technique for norms-adaptable agents in open multi-agent communities. Journal of Systems Science and Complexity. 2016 Dec 1;29(6):1519-37. 